\title{
Os estudos de Estética Urbana e a percepção da cidade artefato no alvorecer
}

do século $X X$

Manoela Rossinetti Rufinoni*

\section{Resumo}

Com base na análise dos estudos de Camillo Sitte e Charles Buls, o artigo evidencia a contribuição da Estética Urbana para o processo de compreensão do ambiente edificado como patrimônio cultural. No contexto das transformações urbanas em curso ao longo do século XIX e no alvorecer do século XX - sobretudo relacionadas à viabilização da vida moderna nas antigas cidades -, diversos estudiosos buscaram instrumentos teóricos e práticos para compreender essas estruturas urbanas e orientar sua transformação. Nessa busca, Sitte e Buls, entre outros, voltaram-se à cidade construída como objeto histórico e cognitivo, diferentemente da maioria dos técnicos urbanistas do período que procuravam solucionar os problemas urbanos aplicando teorias gerais a casos específicos, sem necessariamente atentar para as especificidades históricas desses espaços e suas qualidades irreproduzíveis. A compatibilização entre as estruturas urbanas preexistentes e a viabilização das necessidades de desenvolvimento é, contudo, tema sempre atual. Nesse sentido, as breves análises aqui enunciadas nos oferecem importantes subsídios teóricos para a compreensão do processo histórico de delineamento do conceito de patrimônio urbano; e lançam luzes, ainda, sobre caminhos interpretativos obscurecidos pela prática urbanística posterior.

Palavras-chave: Estética urbana. Patrimônio urbano. Patrimônio cultural.

The Urban Aesthetic and the perception of the artifact city at the dawn of the twentieth century

\section{Abstract}

Based on the analysis of Camillo Sitte and Charles Buls studies, the article discusses the contribution of the Urban Aesthetics in the understanding process of the built environment as cultural heritage. In the context for urban transformations throughout the nineteenth and early twentieth century - particularly related to the viability of 
modern life in ancient cities -, several thinkers sought theoretical and practical tools for understanding these urban structures and guide their transformation. In this search, Sitte and Buls, among others, studied the city as a historical and cognitive object, unlike most urban planners of the period who sought to solve urban problems by applying general theories to specific cases, usually without observing the historical specificities of these spaces and their irreproducible qualities. The attempt to strike a balance between old and new urban spaces, seeking to meet the development needs, however, is always an actual theme. In this sense, the brief analysis described here provide us with important theoretical basis for understanding the historical processes related to the elaboration of the urban heritage concept; and shed light also on interpretive trends obscured by the subsequent urban practice.

Key-words: Urban aesthetic. Urban heritage. Cultural heritage.

Ao longo do século 19 - e com maior vigor a partir da década de 1880 - , diversos estudiosos e intelectuais debruçaram-se sobre as especificidades da cidade preexistente, buscando compreender sua estrutura e desvendar seu papel simbólico (1). Frente aos radicais processos de transformação urbana em curso nesse período, personagens como Victor Hugo, John Ruskin, Carlo Cattaneo, Camillo Boito, entre tantos outros, voltaram-se ao tema da cidade antiga a partir de diferenciadas abordagens, desde manifestações literárias que enalteciam suas características e lamentavam sua transformação, até a promoção de debates em defesa de sua conservação ou, ainda, de estudos técnicos e analíticos que intentavam compreendê-la - como as elaborações conceituais da chamada estética urbana, objeto do presente texto. Na variedade de suas argumentações, tais estudos não se limitaram ao romantismo nostálgico, mas buscaram prefigurar possíveis cenários para o futuro; não necessariamente a partir da proposição de modelos a serem seguidos, mas sim a partir da afirmação de um olhar diferenciado para as preexistências construídas, um olhar que as considera como objeto cognitivo, portador de memórias, saberes e fazeres a serem valorizados e porventura tutelados. 
A releitura dos teóricos da estética urbana em tempos recentes não é novidade. Desde as últimas décadas do século 20, sobretudo a partir de 1960, diversos estudiosos têem se voltado ao tema, buscando instrumentos de compreensão do ambiente urbano em outros moldes, para além das leituras consagradas por determinadas práticas urbanísticas associadas ao movimento moderno. Também no universo acadêmico tem sido notável o aprofundamento do tema, tanto no Brasil quanto no exterior, com grande destaque para as pesquisas sobre a circulação e repercussão dos estudos de estética urbana na prática urbanística do início do século 20 , ou seja, análises sobre a incorporação desses preceitos na elaboração de projetos urbanos em diferentes países e escalas (2). Estudos voltados à evidenciação da estética urbana como caminho investigativo rumo à percepção da cidade artefato, no entanto, ainda são escassos, não obstante as significativas análises elaboradas em ambiente italiano (3). Intentamos no presente artigo, portanto, lançar luzes sobre este aspecto em particular: a contribuição dos estudos de estética urbana como instrumento de análise que toma a cidade como objeto histórico e cognitivo, como elemento portador de valores a serem identificados, indagados e interpretados. Nessa asserção, o processo histórico de maturação do conceito de patrimônio urbano emerge com maior nitidez e nos auxilia a compreender os necessários enlaces entre a produção de novos espaços e a identificação e conservação das preexistências de interesse cultural, no passado e no presente.

\section{Considerações iniciais}

A atribuição de valor histórico, estético e memorial aos conjuntos arquitetônicos e aos tecidos urbanos são temas que começaram a ganhar força sobretudo ao longo do século 19. Diante das incisivas transformações em curso no contexto europeu impulsionadas seja pela atividade industrial, seja pelas significativas alterações nas relações políticas, econômicas e sociais - , evidenciou-se a magnitude e rapidez com que os antigos cenários urbanos se dissolviam, abrindo caminho para a percepção do ambiente edificado como um artefato cultural.

A transformação da cidade, no entanto, foi apenas uma dentre tantas mudanças que então se evidenciavam ao longo do século 19. Esse cenário em mutação foi 
acompanhado de um complexo conjunto de discussões em diversos campos do saber, como o surgimento de novas teorias sociais que procuravam responder ao dilema da classe trabalhadora; a consolidação das identidades nacionais europeias, notadamente a partir de referenciais nas artes e na arquitetura; os novos questionamentos sobre a historiografia das artes e sobre a própria estética como disciplina; e, lado a lado a tantos conceitos em ebulição, o próprio desenvolvimento dos campos disciplinares voltados à preservação, à restauração e ao urbanismo.

O rápido crescimento de algumas das principais cidades europeias - principalmente Londres e Paris - provocou uma série de disfunções urbanas nunca antes imaginadas, geradas pela impossibilidade da cidade medieval em responder às demandas funcionais da industrialização. Dentre tantos fatores, o grande fluxo populacional proveniente das migrações campo-cidade, a necessidade de novas construções para abrigar funções produtivas e a insuficiência das estruturas existentes face às novas necessidades foram alguns dos principais conflitos que exacerbaram a noção de ruptura entre o passado e o presente. Como elementos transformadores que ameaçavam a integridade dos tecidos urbanos antigos, os espaços gerados pela industrialização (assim como as novas demandas sociais e urbanas) em grande parte impulsionaram o debate sobre os possíveis valores das preexistências urbanas que então se perdiam.

De um lado, voltam-se as atenções para a importância da cidade antiga diante das demolições e descaracterizações provocadas por essas transformações - cidade esta formada em grande parte por edificações medievais, góticas, estilo então eleito como representativo das culturas inglesa e francesa. A partir dessa vertente de estudos desenvolver-se-ão grande parte das discussões sobre a preservação dos monumentos no século 19, com destaque para os escritos de John Ruskin e William Morris (4). De outro lado, será posta em questão a necessidade de interferir na cidade antiga para adequá-la às novas necessidades e rendê-la mais higiênica e eficiente. Esta é a abordagem desenvolvida pelos precursores do urbanismo que, a partir da tentativa de solucionar os problemas da cidade industrial, desenvolverão teorias e práticas de intervenção no tecido preexistente. As teorias de Ildefonso Cerdà e as reformas de Haussmann são grandes exemplos nesse sentido. 
Entre meados do século 19 e início do século 20, ao lado das primeiras iniciativas práticas de intervenção sobre a cidade preexistente, diversos autores desenvolveram reflexões e análises sobre o ambiente urbano em seus múltiplos aspectos e abriram caminho para o delineamento da disciplina Urbanismo (5). Nesse contexto, ao se voltarem ao estudo da cidade, tais estudiosos buscaram instrumentos teóricos e práticos para compreender a sua estrutura, composição e trajetória, bem como para tentar orientar a sua transformação.

Não obstante a identificação de relações de causa e efeito entre as indagações que delinearam o nascimento da disciplina do urbanismo e aquelas que concorreriam para a invenção do patrimônio urbano, cabe ressaltar que ambos os caminhos não convergem numa mesma direção. E tratar de tais temas - ora solidários, ora antagônicos - é tarefa que se reveste de certos cuidados. Sabemos que a ampliação dos estudos urbanos e a consequente transformação da cidade antiga em objeto de estudo e investigação, notadamente no final do século 19 , ocorreu mais pelo efeito de oposição, ou contraste, entre o tecido antigo e a cidade moderna que se formava, do que propriamente por um interesse objetivo pelo seu valor histórico e pela sua preservação. Françoise Choay adverte que a contraposição entre as cidades do passado e a cidade do presente não significou o desejo de conservar as primeiras, o processo foi outro:

[...] quer o urbanismo se empenhasse em destruir os conjuntos urbanos antigos, quer procurasse preservá-los, foi justamente tornando-se um obstáculo ao livre desdobramento de novas modalidades de organização do espaço urbano que as formações antigas adquiriram sua identidade conceitual. (CHOAY, 2001, p. 179).

Dessa forma, é importante salientar que a análise das relações entre contribuições teóricas advindas de diferentes campos disciplinares - da história da arquitetura, da preservação e dos estudos urbanísticos -, como instrumento para compreender a maturação do conceito de patrimônio urbano, pressupõe a tessitura cuidadosa entre caminhos investigativos que até então pouco se tocaram, apesar dos evidentes antecedentes comuns que o complexo contexto histórico e cultural do século 19 lhes proporcionou. 
No cenário das transformações em curso ao longo do século 19, uma série de elementos condicionariam as variadas formas de refletir sobre a cidade $e$ a sociedade que a produzia. De um lado, o nascente urbanismo nutria-se dos debates e reflexões sobre o ambiente urbano do ponto de vista filosófico e social, na variedade de suas manifestações (6); e de outro, moldava-se a partir do embate com um série de questões de ordem técnica que emergiam desse cenário em mutação. Ao lado dos desafios gerados pelas novas invenções técnicas, com destaque para a radical transformação do território impulsionada pela implantação das ferrovias, ganhavam corpo os questionamentos dos higienistas sobre a salubridade urbana e a busca de soluções para remediar os problemas sanitários das cidades industriais. Nesse contexto, questões como a proliferação de epidemias, o congestionamento das cidades, a inexistência de regras para o uso dos terrenos e até mesmo o tratamento de detritos e contaminação dos rios, ocupavam o centro dos debates e impulsionavam a elaboração dos primeiros relatórios sanitários, propostas legislativas (7) e intervenções práticas sobre o tecido urbano preexistente.

Nesse sentido, as obras de Haussmann em Paris representam o exemplo por excelência. O conjunto de reformas urbanas realizadas a partir da década de 1850, ao propor a reestruturação viária da cidade por meio da sobreposição de uma nova malha de vias largas e retilíneas sobre a antiga Paris, provocou a destruição de grande parte dos bairros medievais e colocou em pauta, pela primeira vez nesta escala, os problemas da relação antigo-novo na intervenção sobre a cidade antiga (8). Independentemente das características positivas ou negativas atribuídas ao projeto de Haussmann pela historiografia crítica, a experiência de Paris abriu caminho para uma série de projetos urbanos supostamente inspirados em Haussmann, mas que nem sempre, porém, alcançaram resultados urbanísticos que justificassem as grandes demolições realizadas. Por outro lado, a experiência haussmanniana teria ainda contribuído para a difusão de uma prática que se tornava corrente, $\mathrm{o}$ isolamento de determinados monumentos arquitetônicos a partir da 'desobstrução' de seus arredores, ou seja, da demolição das edificações adjacentes consideradas sem valor. Notamos, portanto, que os principais elementos que delineavam os alcances da nova disciplina do urbanismo, nesse momento pouco se relacionavam com a discussão sobre a interferência de tais práticas sobre a cidade antiga considerando os seus possíveis valores históricos, estéticos e memoriais. Os 
teóricos contemporâneos que enalteciam os valores da cidade preexistente e condenavam a sua destruição, como Ruskin e Morris, entraram para os anais da história do urbanismo muito mais devido às suas críticas de caráter social associadas à industrialização do que propriamente pela defesa das cidades antigas.

\section{Camillo Sitte e a percepção das especificidades da cidade antiga}

$\mathrm{Na}$ última década do século 19 , no entanto, os estudos do arquiteto austríaco Camillo Sitte (1843-1903) abrem caminho para a aproximação entre a valorização da cidade preexistente e a abordagem dos problemas urbanísticos do período. A partir da análise da composição urbana das cidades medievais, Sitte atenta para a dimensão estética dos conjuntos edificados e busca enfatizar o caráter artístico da cidade e a repercussão de suas qualidades compositivas na percepção daqueles que a vivenciam. Suas considerações, reunidas na obra Der Städtebau, o colocam em franca oposição aos projetos urbanísticos do período em grande parte influenciados pelas reformas de Haussmann, como o projeto para a Ringstrasse de Viena, um dos temas de seu estudo (9). A obra de Sitte interessa-nos como uma importante referência dentre os estudos urbanísticos, por um lado, devido ao caráter inovador de sua abordagem e consequente ressonância sobre outros teóricos tanto no campo do urbanismo como na preservação dos monumentos, como Charles Buls e Max Dvořák -, por outro lado, devido às severas críticas que recebeu de teóricos do movimento moderno ao longo de várias décadas, fato que evidenciaria a abertura de percursos distintos com relação à intervenção sobre o tecido preexistente.

Tomando o tema da praça pública como ponto de partida, Sitte analisou a composição estética e as relações de escala entre os elementos que compõem o espaço urbano das cidades pré-industriais. Por meio do emprego de numerosos desenhos e exemplos práticos buscou evidenciar as qualidades projetuais desses conjuntos urbanos, as relações espaciais entre as praças e os edifícios públicos adjacentes, a escala do observador e os efeitos de perspectiva e percurso. Questões que, segundo o autor, o monótono urbanismo moderno não pretendia considerar. A partir de tais análises, condena uma série de recursos projetuais adotados pelo desenho moderno como a recorrência arbitrária ao centro livre na 
concepção das praças ou o isolamento de edifícios sem atentar para as imprescindíveis relações de escala com o entorno, questão de composição que os sensíveis construtores antigos produziam espontaneamente e que "nós, armados de réguas e compassos" e "com uma geometria canhestra" (SITTE, 1992, p. 35) tentamos inutilmente alcançar.

A localização dos edifícios no centro das praças, sejam eles projetos novos ou edifícios antigos cujas construções adjacentes foram demolidas, é um recurso amplamente condenado por Sitte, um "pedantismo moderno que decorre, naturalmente, do movimento do compasso e da régua sobre a prancheta, sem manter relação alguma com o quadro formado na realidade" (SITTE, 1992, p. 79). Segundo tal disposição, a harmonia viva e orgânica entre os edifícios e seus arredores, bem como os efeitos de perspectiva, seriam totalmente anulados, conferindo à construção isolada o triste aspecto de "uma torta exposta numa bandeja" (SITTE, 1992, p. 42). E tal isolamento seria ainda mais grave quando envolve monumentos antigos. Nesse caso, a demolição do entorno anula o efeito de toda a composição da obra, certamente pensada a partir da integração com o ambiente circundante, subtraindo, portanto, um dos fundamentos essenciais de sua concepção. Segundo Sitte, essa "obsessão pelo isolamento de edifícios é um modismo nefasto" e atribui tal prática aos teóricos contemporâneos, como Reinhard Baumeister (1876), que defendera o isolamento praticamente como uma norma, como um recurso para "desimpedir" as construções antigas (10). Tal prática teria provocado intervenções inusitadas como o isolamento de antigos portões de burgos desconsiderando completamente a natureza de sua existência: "De fato, uma coisa muito bonita, isso de um portão que não se atravessa, mas em torno do qual se passeia!" (SITTE, 1992, p. 46).

Cabe ressaltar que os elementos analisados por Sitte - a composição dos traçados urbanos antigos, a incidência dos fatores ambientais sobre o projeto urbano, as relações de escala entre os espaços edificados, vias e praças, os efeitos de perspectiva gerados pela sinuosidade das ruas - não objetivaram a imitação indiscriminada de tais composições na atuação contemporânea sobre a cidade, como acreditaram alguns teóricos, mas sim a apreensão do que chamou de 'essência' das obras urbanas antigas. O autor buscava, diante da insatisfação para 
com as intervenções urbanas modernas, desvendar os princípios projetuais geradores dos tecidos urbanos antigos, por ele considerados harmoniosos e acolhedores, para que pudessem ser aplicados com sensatez às necessidades da atualidade ou, na impossibilidade de tal aplicação, para que fossem ao menos preservados como patrimônio (11).

Não obstante a crítica severa à falência artística dos recursos projetuais dos chamados "sistemas modernos" (SITTE, 1992, p. 100), o autor não deixa de atentar para a importância do atendimento aos requisitos de higiene, salubridade e circulação, focos da discussão sobre a cidade nesse momento. Não pretende, no entanto, perseguir tal abordagem. E o autor esclarece os alcances de seu estudo logo no início da obra. Afirma que deseja evidenciar e compreender os motivos da composição artística das cidades a partir da análise técnica e científica das mesmas, sejam elas antigas ou modernas (SITTE, 1992, p. 15). E em outras passagens esclarece ainda que não pretende promover a imitação de antigos desenhos, e sim o estabelecimento de um paralelo entre os mesmos e as condições e solicitações da atualidade.

Esse estudo não tem como objetivo promover a aplicação da chamada beleza pinturesca dos conjuntos urbanos antigos no contexto das propostas modernas, pois, sobretudo neste âmbito, faz jus o ditado: "A necessidade é mestra". Tudo o que já se evidenciou como necessário segundo aspectos higiênicos ou por outros motivos prioritários deve ser realizado ainda que em detrimento dos motivos pinturescos, sejam estes quais forem. Porém, esta conviç̧ão não nos deve impedir de investigar minuciosamente todos os motivos pinturescos das cidades antigas, estabelecendo um paralelo entre eles e as condições modernas, para que assim possamos esclarecer os aspectos artísticos desta questão, bem como identificar com precisão o que ainda pode ser resgatado, em nosso benefício, das belezas dos conjuntos urbanos antigos, conservando-as ao menos como patrimônio.

[...] Mas é possível inventar e construir em uma planta todas as casualidades geradas no decorrer dos séculos? [...] Certamente que não. [...] A vida moderna e a moderna técnica de construção não mais comportam uma imitação fiel dos complexos urbanos antigos - e não aceitar essa conclusão significa entregar-se a um devaneio infrutífero. As magníficas obras antigas [...] devem permanecer vivas entre nós de outro modo que não através da imitação insensata; e apenas quando apreendermos sua essência e conseguirmos aplicá-la com sensatez às circunstâncias modernas é que será possível obter ainda uma colheita florida de uma terra que se tornou estéril. (SITTE, 1992, p. 29-30, 117). 
No entanto, diversas interpretações posteriores, embebidas pelos pressupostos do urbanismo moderno que se afirmariam notadamente após a década de 1930, conferiram-Ihe por muito tempo os rótulos de passadista e retrógrado. Siegfried Giedion o acusa de querer "voltar à cidade medieval", Le Corbusier, por sua vez, ironiza os seus princípios rotulando-os de "a religião dos estúpidos" e, analogamente, condena os traçados irregulares supostamente propostos por Sitte afirmando tratar-se de "caminhos para asnos" (LE CORBUSIER, 1923, p. 9) (12). Ainda na década de 1960 há referência sobre sua obra como sendo obsessiva em relação aos aspectos estéticos e ignara quanto à evolução das condições de trabalho e dos problemas de circulação (13). Certamente Sitte não aprofundou tais problemas, que aliás não compunham o escopo sobre o qual se debruçara, mas não por desconhecimento da problemática. O conjunto de solicitações da vida moderna estão presentes ao longo da obra sob a forma de contraponto a toda sua argumentação, já que a compreensão da artisticidade urbana é buscada justamente diante da interferência modernizadora sobre a cidade antiga. Grande parte das interpretações de sua obra, portanto, repousam na incompreensão do objeto central de sua análise. Em Sitte, a cidade medieval é tomada como um artefato, um organismo que comporta saberes, tradições, e ao qual nos voltamos em busca do conhecimento, daí a valorização de sua historicidade. Não se trata de um modelo a ser copiado, mas sim da evidenciação de um conjunto de felizes soluções regidas por qualquer princípio artístico, o qual devemos compreender e com o qual devemos dialogar em consonância com as atuais necessidades, de modo que a satisfação das mesmas não seja alcançada somente em detrimento de toda artisticidade urbana.

[...] seria uma espécie de cegueira não reparar nas eminentes conquistas da construção urbana moderna em relação aos antigos no âmbito da higiene. [...] Resta-nos [...] saber se, de fato, tais êxitos só podem ser obtidos pelo preço terrível da renúncia a toda beleza artística dos conjuntos urbanos. (SITTE, 1992, p. 116).

A observação da crítica dos urbanistas modernos aos princípios sittianos nos interessa para pontuar um momento crucial na delimitação dos caminhos operativos com relação ao tratamento do patrimônio urbano. De um lado, Camillo Sitte 
impulsiona a valorização dos tecidos antigos enquanto composição e estrutura, evidencia as especificidades estéticas do conjunto urbano e não apenas do monumento e seu entorno imediato e busca alinhavar, no limite do alcance histórico de suas análises, as conquistas do urbanismo e a importância da cidade antiga. De outro lado, despontam e paulatinamente se fortalecem os princípios do urbanismo moderno. Na esteira das teses e propostas de Otto Wagner, seguem-lhe outros teóricos e suas respectivas análises: Tony Garnier, Walter Gropius, Le Corbusier, entre outros (14). No quadro da presente abordagem, tais teóricos abririam caminho para a priorização das respostas da técnica e do redesenho urbano em detrimento da cidade preexistente. As estruturas antigas até poderão ser respeitadas, desde que não interfiram na reordenação dos espaços, como se afirmará anos mais tarde na Carta de Atenas do CIAM, de 1933 (15). No campo da preservação urbana, notadamente no contexto europeu, o embate entre as propostas urbanísticas, legislativas ou projetuais, consideradas mais conservadoras e atentas ao patrimônio preexistente e aquelas de influência marcadamente moderna, que defendiam a construção de novas estruturas como prioridade, será constante ao longo de todo o século 20 .

\section{Charles Buls e a Estética das Cidades}

No que tange à contribuição dos estudos de estética da cidade para a concepção do patrimônio urbano, cumpre destacar as análises desenvolvidas pelo belga Charles Buls. Impulsionado pela obra de Camillo Sitte e nove anos antes de suas preciosas contribuições no campo da preservação dos monumentos (BULS, 1903), Buls dedicou-se ao estudo estético dos ambientes urbanos e procurou elaborar princípios gerais de atuação sobre tais espaços, apresentados no estudo intitulado Estética das Cidades, publicado em 1893 (16). De posse de certa estruturação teórica na esfera urbanística e também de significativa experiência prática no campo da administração urbana, Buls seria o responsável por um importante passo em direção à integração entre os temas do urbanismo e aqueles da tutela, ainda que o peso teórico dessa aproximação somente anos mais tarde viesse a apresentar resultados significativos, a partir da contribuição cumulativa de outros teóricos. No entanto, nesse momento são raros os estudiosos que transitam em ambos os campos 
disciplinares. Até mesmo em Camillo Sitte encontramos poucas referências, e em geral de passagem, à questão específica da preservação.

A obra Estética das Cidades foi escrita sob a clara repercussão das propostas de Sitte, num momento no qual Buls, prefeito de Bruxelas, defrontava-se com um projeto urbano que ameaçava destruir um importante bairro histórico da capital. Igualmente desapontado com os pressupostos urbanísticos em difusão nas principais cidades europeias, sente-se impulsionado a formular diretrizes para as novas expansões urbanas buscando, de certo modo, propor soluções de mediação entre as reformas necessárias e a preservação da cidade preexistente. Dessa forma, defende a análise atenta dos projetos urbanos efetivamente necessários para as adaptações modernas, de modo a minimizar tanto quanto possível as intervenções sobre os bairros antigos, evitando demolições excessivas e permitindo o acesso dos habitantes às melhorias almejadas.

Seguindo de perto as considerações de Sitte, Buls retoma uma série de argumentos sobre a natureza estética das cidades pré-industriais - cuja beleza estaria relacionada ao caráter espontâneo de seu surgimento e crescimento: a relação entre a construção e a paisagem - atentando para a influência da disposição natural do terreno nas composições urbanas e a valorização do caráter agreste de certas localidades; a inconveniência de isolar monumentos originalmente concebidos entre massas construídas - tema também abordado em seus estudos sobre restauração (BULS, 1903) (17); e a forte crítica aos recursos projetuais modernos. Nesse sentido, sua posição está bem clara logo no início do estudo. O autor abre o tema ressaltando as características estéticas das composições urbanas antigas e prossegue, logo mais, atentando para a evidente diferença qualitativa entre esses conjuntos e a parte moderna da cidade construída segundo a nova ordem.

As antigas cidades e as antigas estradas têm um encanto particular para os espíritos delicados e sensíveis às impressões da arte. Não se poderá dizer que sejam belas, contudo agradam por aquela desordem que não provém da arte, mas do acaso se todavia ao acaso pode-se atribuir o efeito devido ao crescer das habitações ao longo de um caminho sinuoso, que pouco a pouco se tornou uma via. [...] Quando se lança o olhar sobre o plano de uma das nossas grandes cidades, pode-se distinguir à primeira vista a parte antiga da parte moderna: a primeira é formada por uma rede de estradas, que se ramificam e se amarram 
como as artérias e as veias de um organismo vivo; a segunda com as suas vias paralelas e perpendiculares tem o caráter de uma cristalização artificial árida e matemática. (BULS, 1999, p. 317, tradução nossa).

Não condena completamente, no entanto, a ordem simétrica dos novos traçados, por vezes destinada a conferir um caráter grandioso e monumental a certas partes da cidade, mas alerta para a recorrência insensata aos planos urbanos vistos a voo de pássaro, ou seja, para a busca de simetrias e desenhos sobre o papel que jamais poderiam ser notados em um passeio real pelo ambiente construído. Tal tema também foi abordado por Sitte e ressalta a preocupação de ambos os autores com a perspectiva do ponto de vista do pedestre e com as relações sensíveis experimentadas no contato direto com a cidade, evidenciação de uma urbanidade que os sistemas modernos vindos da prancheta não poderiam fornecer.

Com relação à busca de soluções alternativas e mediadoras para a intervenção sobre os bairros antigos, grande interesse nos reserva o recurso proposto para a abertura de vias. Buls propõe que sejam aproveitadas, sempre que possível, as vias e percursos já existentes, ampliando-os e adaptando-os, ao invés de criar novas aberturas que destruiriam grandes parcelas dos bairros antigos. Segundo tal critério, "conserva-se à cidade o seu caráter local e nacional, não se destroem as lembranças do passado senão na estrita necessidade das exigências modernas, obtém-se efeitos pitorescos, tem-se prudência para com as finanças municipais, e incomoda-se menos os costumes e os interesses da população" (BULS, 1999, p. 319). Não obstante as evidentes dificuldades de aplicação prática, o método proposto, além de minimizar as demolições, permitiria ainda seguir uma conformação espacial própria do contexto urbano de origem.

Essa solução baseou-se nos estudos de Charles Van Mierlo, engenheiro muito admirado por Buls e textualmente referenciado na Estética. Em projeto datado de 1885, Van Mierlo atentou para a concepção de uma malha viária estreitamente relacionada com o funcionamento global da cidade e com suas características topográficas. Nesse sentido, o engenheiro procurou considerar os fluxos de circulação gerados por diferentes atividades, os diversos aspectos de ordem técnica envolvidos, a valorização imobiliária dos terrenos e as melhores alternativas para 
evitar a demolição de monumentos importantes ou para explorar a oportunidade de colocá-los em evidência (SMETS, 1992, p. 73). A defesa de tal recurso na tentativa de buscar uma mediação entre a conservação do existente e as transformações impetradas pelo desenvolvimento urbano coloca Charles Buls dentre os teóricos que abririam caminho para a concepção do chamado diradamento edilizio, método mais tarde desenvolvido pelo italiano Gustavo Giovannoni (GIAMBRUNO, 2001, p. 46) (18).

Além da contribuição da Estética, cabe destacar a atuação de Charles Buls na criação, em 1894, do movimento l'Fe d'utilité publique, em Bruxelas, ao lado de personagens como Victor Horta e Eugène Broerman. O movimento tinha como objetivo "revestir de uma forma artística tudo o que o progresso adquiriu de útil à vida contemporânea" (BROERMAN apud SMETS, 1977), abarcando, certamente, as questões relacionadas ao planejamento das cidades. Durante cerca de duas décadas o grupo promoveu congressos, debates e concursos de projetos, além da publicação da revista mensal L'Art Public, lançada em 1905, ano da criação do Institut International d'Art Public. Contando com a colaboração de personagens como Joseph Stübben, Louis Cloquet, Jean Claude Nicolas Forestier e Walter Crane, as atividades do Instituto buscaram abordar quatro eixos principais: a cultura estética, a conservação do patrimônio artístico, a proteção dos sítios naturais e a estética das cidades (BERTONI, 2006, p. 5).

Tanto em Sitte quanto em Buls, notamos a construção de um esquema teórico baseado na crítica artística e arquitetônica, na observação atenta de exemplos práticos e na recorrência a um amplo repertório iconográfico para desvendar as possíveis origens projetuais dos tecidos antigos. Ambos, portanto, voltaram-se à cidade construída como objeto histórico e cognitivo, diferentemente da maioria dos técnicos urbanistas do mesmo período que procuravam solucionar os problemas urbanos aplicando teorias gerais a casos específicos, sem necessariamente atentar para as particularidades dos espaços preexistentes.

\section{Notas sobre a repercussão dos estudos de estética urbana}


Os princípios sittianos repercutiram na produção de vários teóricos, notadamente no início do século 20, e abriram caminho para diferentes projetos urbanos, quer seja de intervenção sobre a cidade existente, quer seja de novos bairros cujos desenhos tomavam por base os elementos projetuais enunciados por Sitte e seus sucessores.

$\mathrm{Na}$ variedade de suas teorias, encontramos nos escritos e projetos de diversos autores a recorrência aos pressupostos da chamada estética urbana, fato que, de certo modo, evidencia a adoção de um ponto de partida inovador no que tange ao estudo e orientação das transformações urbanas; qual seja, o percurso investigativo que toma por base a cidade existente e as lições de desenho que tais agrupamentos construídos poderiam nos fornecer. E Camillo Sitte foi um dos principais responsáveis por tal inovação. De fato, conforme afirmou Zucconi, tanto o movimento para a cidade jardim, quanto a valorização dos subúrbios residenciais, fenômenos observados desde o início do século 20 e protagonizados por teóricos do urbanismo provenientes de diversos países, seriam expressões da mesma rejeição à transformação urbana denunciada por Sitte, uma resposta à "falta de relações com as imagens confortadoras da tradição" (ZUCCONI, 2009, p. 161), com a cidade artefato que então se delineava como objeto a ser indagado e interpretado.

O arquiteto alemão Hermann Joseph Stübben (1845-1936), considerado um dos defensores da chamada estética urbana, buscou uma fundamentação teórica de certa forma intermediária entre ambas as posições que então despontavam naquele momento. O próprio Stübben declarou-se inflenciado tanto pela vertente que prioriza os aspectos técnicos da intervenção sobre a cidade, representada principalmente por Reinhard Baumeister, quanto pelos estudos que evidenciam os princípios artísticos, propostos por Camillo Sitte. Em sua obra Der Städtebau (Handbuch Der Architektur) (19), publicada um ano depois do estudo de Sitte, Stübben procurou conceber os projetos urbanos considerando a cidade como um todo orgânico. Para tanto recorre a uma série manualística de elementos e exigências a serem observadas - notadamente de ordem técnica como o dimensionamento de equipamentos urbanos e sistemas de engenharia -, conferindo à sua obra um caráter verdadeiramente enciclopédico (20). Em sua visão da cidade como um todo orgânico, considera como prioridade a funcionalidade do sistema, o qual, sendo funcional, será certamente belo. A sua busca pela compatibilidade entre a técnica e 
a estética urbana, portanto, repousaria na crença da solução integrada de todas as questões envolvidas. Apesar de considerar os aspectos artísticos a partir da influência sittiana, como o próprio autor declara, a aplicação de tais prerrogativas sobre a cidade antiga, objeto de Sitte, dificilmente poderia garantir a conservação da artisticidade por este evidenciada (21).

A historiografia do urbanismo atribui a Sitte e seus discípulos a influência sobre várias linhas projetuais que se desenvolveriam no alvorecer do século, de orientação contrária às operações de cunho haussmanniano, em um momento no qual o conhecimento especializado no campo do urbanismo começava a atingir certa repercussão, inicialmente a partir da discussão de teorias e projetos em congressos e encontros internacionais e, em seguida, a partir da publicação dos primeiros estudos teóricos e suas respectivas traduções (SIMÕES, 2008). Nesse sentido, o historiador alemão Cornelius Gurlitt (1850-1938), por exemplo, a partir da matriz sittiana, defendeu a elaboração de planos urbanísticos que atentassem para a quebra da monotonia dos percursos e explorassem os "ritmos da melodia urbana".

Já o urbanista inglês Raymond Unwin (1863-1940), dentre outros aspectos, ressalta a valorização do traçado viário como componente de desenho dotado de especificidades próprias e não somente como o negativo com relação à parte edificada. Em Werner Hegemann (1881-1936), arquiteto e urbanista alemão, a mensagem de Sitte pode ser observada na ênfase com a qual analisa os conjuntos arquitetônicos antigos. Hegemann considera os conjuntos edificados como composições formadas por cheios e vazios e dotadas de uma estética particular que seria responsável pela fruição de certa continuidade histórica e simbólica em cidades ameaçadas pela constante transformação. Dessa forma, considera os espaços entre as construções, a praça, suas formas e escalas, a continuidade e a regularidade dos edifícios que a enquadram, tão importantes quanto o monumento arquitetônico isolado (22).

Também no contexto brasileiro tais estudos urbanos lograram considerável repercussão. Não obstante as diferenças entre o contexto europeu que delineava a problemática urbanística e aquele das transformações urbanas brasileiras no início do século, tanto o modelo haussmanniano, quanto algumas das ideias vinculadas à 
estética urbana estiveram presentes na elaboração de projetos modernizadores para várias cidades brasileiras (23). Nesse momento, no entanto, o contexto histórico e cultural brasileiro ainda não criara as condições de partida para a discussão sobre a interferência de reformas dessa envergadura do ponto de vista da conservação do patrimônio urbano existente.

No cenário europeu que moldara as manifestações teóricas abordadas, a variedade de caminhos interpretativos em torno do tema urbano evidencia um momento de conflito entre diversas preocupações em jogo: a compreensão do novo, a apropriação do progresso, a valorização do passado e a salvaguarda de seus testemunhos. No cerne da chamada estética urbana estão, pois, evidentes, as tensões de fim de século representadas pelo conflito entre o desejo de conservar a cidade antiga e a constatação de sua necessária tranformação, ou seja, a manifestação no campo urbanístico das tensões em torno da modernidade (BIANCHETTI, 1999, p. 11).

Com a disseminação dos pressupostos modernistas no campo do urbanismo, notadamente a partir da Carta de Atenas do CIAM, a contribuição das investigações sobre a cidade preexistente na intervenção prática sobre a cidade contemporânea não prosseguirá com a mesma força argumentativa desses primeiros teóricos, afastando-se pouco a pouco das práticas predominantes na atuação sobre a cidade.

A partir de então, a discussão sobre o patrimônio urbano - sobre a percepção da cidade como artefato cognitivo - desenvolver-se-á mais no âmbito da preservação dos monumentos do que propriamente no campo do urbanismo, esfera disciplinar que efetivamente intervinha sobre a cidade. Releituras das investigações urbanísticas ora apresentadas, nas quais a cidade preexistente assumia o foco central, ganhariam espaço sobretudo a partir dos anos 1960, no contexto de revisão de certos pressupostos do urbanismo moderno, com destaque para os estudiosos italianos da chamada Escola de Veneza, como Giorgio Piccinato, Carlo Aymonino e Donatella Calabi; bem como os pesquisadores franceses vinculados ao Centro de Sociologia Urbana. 


\section{Notas}

(1) O presente artigo desenvolve temas previamente enunciados em RUFINONI, 2009.

(2) Dentre as diversas referências nesse sentido, destacamos os estudos sobre Camillo Sitte elaborados por ocasião do Convegno Internazionale Camillo Sitte e i suoi interpreti, realizado em 1990 na cidade de Veneza (ZUCCONI, 1992), o Symposium Camillo Sitte, realizado em Viena, em 2003, a Giornata di Studio Camillo Sitte, realizada também em Veneza, em 2004 e o Congresso Internacional Camillo Sitte e a circulação de ideias de estética urbana: Europa e América Latina 1880-1930, realizado em 2004 na cidade de Agudos, São Paulo (CALABI, PROFYRIOU, RETTO Jr., 2006).

(3) A repercussão dos estudos de estética urbana na discussão sobre a preservação de centros históricos na Itália pode ser observada desde as elaborações conceituais de Gustavo Giovannoni, até os debates impulsionados pelo segundo pós-guerra. Cf.: RUFINONI, 2009. Sobre a recepção dos estudos de Camillo Sitte na Itália, Zucconi (2006, p.4-5) afirma que, no país, seu livro foi lido, desde o início "sob o signo de uma dupla matriz, urbanística e conservacionista. O texto foi apresentado primeiramente na versão francesa de Camille Martin, depois na versão italiana editada em 1907, de forma abreviada e com o título Notas sobre a Arte de Construir a Cidade." Cf.: PICCINELLI, 1992, p.29 et seq.

(4) Como observa-se na leitura dos clássicos textos A Lâmpada da Memória [1849], de John RUSKIN (2008) e The Society for the Protection of Ancient Buildings [1877], de William MORRIS (2004).

(5) Ildefonso Cerdà (1867) empregou o termo urbe para designar os diferentes tipos de assentamentos humanos e o termo urbanização para referir-se à ação sobre a urbe. Com base em tais termos cunhados por Cerdá surgirá posteriormente, no início do século 20 , a palavra urbanismo para então denominar a nova disciplina.

(6) A este respeito cabe destacar os estudos dos chamados socialistas utópicos - como Robert Owen, Charles Fourier, Etiene Cabet, entre outros -, pensadores que denunciaram os problemas urbanos e buscaram propor modelos de cidades (e sociedades) ideais, ao longo da primeira metade do século 19. Analogamente, destacamse as análises nos campos da Sociologia e da Filosofia, sobretudo relacionadas à influência das teorias do Liberalismo econômico, do Positivismo e do Marxismo no desenrolar dos fatos urbanos naquele período. Sobre tais temas, consultar DE FUSCO, 2000, p. 6-18; CHOAY, 2001, p. 1-56; BENEVOLO, 2001, p. 74-82.

(7) No contexto inglês, destacam-se as leis sobre saúde pública, como o Public Health Act, de 1848; o Artisan's and Labourer's Dwelling Act, de 1866; e o Housing of Worker Class Act, de 1890. Na França, apesar dos caminhos operativos terem sido outros, as motivações foram semelhantes. Um decreto promulgado em 1853 permitiu alterações na regulamentação da expropriação de terrenos urbanos, antes considerada apenas em caráter excepcional, e a transformou em um instrumento urbanístico que outorgou poderes às autoridades públicas para intervir na cidade. Tal instrumento teria sido a base legal que permitira a Haussmann a realização das reformas de Paris. Na Itália, destaca-se a Lei de 1865 sobre expropriação urbana para utilidade pública que provocou uma série de demolições em centros históricos considerados insalubres (BENEVOLO, 2001, p. 345346; CALABI, 2001, p.104; GIULIANI, 1966, p.10).

(8) As obras de Haussmann em Paris suscitam estudos e aprofundamento sob diferenciados aspectos. Um aspecto de grande relevância é o fato de Haussmann ter sido um dos primeiros a considerar o fator 'tempo' no projeto, ou seja, a considerar as projeções de transformação no futuro. Por outro lado, Benevolo (2001, p.96) 
também ressalta influências de caráter político na execução dessas obras que possuiriam o duplo papel de promover a popularidade de Napoleão III, e de tornar as ruas da cidade mais propícias à repressão de levantes populares, a partir da demolição das estreitas ruas medievais e da construção de vias mais espaçosas para o movimento das tropas. Para aprofundamentos sobre as reformas de Haussmann em Paris, além da contribuição referencial de Leonardo Benevolo, consultar as diferenciadas abordagens de Pierre Pinon (2002), Marcel Roncayollo e Thierry Paquot (1992), bem como os estudos da década de 1950 reunidos por Louis Réau (1954).

(9) Com o intuito de lançar luzes sobre a contribuição de Camillo Sitte para a percepção da cidade artefato, abordaremos exclusivamente a sua obra Der Städtebau nach seinen künstlerischen Grundsätzen, publicada originalmente em 1889 e traduzida para o português em 1992. Cumpre salientar, no entanto, a existência de numerosos escritos e projetos de Camillo Sitte ainda pouco estudados e que deverão abrir novos caminhos interpretativos sobre o conjunto de sua obra no futuro: são dezenas de textos sobre arquitetura e urbanismo, música, pintura, história da arte, arts and crafts e pedagogia, além de cartas, desenhos e projetos arquitetônicos e urbanos (BOHL; LEJEUNE, 2008, p.xvii). A obra completa de Camillo Sitte está sendo publicada em Viena, em coletânea composta por seis volumes organizados por Klaus Semsroth, Michael Mönninger e Christiane Crasemann Collins (2008-2011).

(10) Alguns trechos da obra de Reinhard Baumeister foram publicados em italiano no apêndice do estudo de Giorgio Piccinato (1974).

(11) Com relação aos laços entre as elaborações conceituais de Camillo Sitte e os estudos no campo da preservação de monumentos, Zucconi ressalta o convite feito a Camillo Boito para colaborar na revista "Der Städtebau", dirigida por Sitte e Theodor Goecke, funcionário responsável pela tutela de monumentos em Brandeburgo, Alemanha. Sitte justifica o convite citando a atuação e os escritos de Boito em defesa de Veneza, ações que o habilitavam a atuar como correspondente italiano do periódico. Para Zucconi (2006, p.3): "A afirmação de Sitte nos faz compreender que a nova revista Der Städtebau pretendia dar uma resposta abrangente a problemas que muitas vezes eram considerados separadamente: de um lado, a dimensão técnicourbanística, de outro, a dimensão conservacionista. A ideia é justamente criar uma sinergia entre uma e outra, como o próprio binômio Sitte-Goecke estaria a demonstrar."

(12) Carlos Roberto Monteiro de Andrade, autor da Apresentação da edição brasileira de Der Städtebau (1992, p.5), lembra-nos que Sitte não propôs o emprego de nenhum traçado viário em particular. Quem o fez foi Camille Martin, arquiteto suíço autor da primeira tradução francesa publicada em 1902 e em 1918. Tal tradução, além de apresentar fidelidade questionável ao original, trazia um capítulo inteiro de autoria de Martin no qual o tradutor abordava justamente o traçado de ruas. Ainda sobre a tradução francesa, Christiane Crasemann Collins (2005) coautora da tradução da mesma obra para a língua inglesa, publicada em 1965 - ressalta que o significado da obra de Sitte foi em parte comprometido pela tradução de Camille Martin, provavelmente a versão que mais circulou entre estudiosos, até a publicação da tradução para o inglês. Uma detalhada análise crítica sobre a versão de Martin pode ser consultada em COLLINS, G; COLLINS, C., 1965.

(13) Observações de Françoise Choay em sua Antologia cuja primeira edição é de 1965. Em textos mais recentes, no entanto, a abordagem de Choay assume outros contornos, sobretudo a partir do final dos anos 1960, quando a desmistificação do movimento dos CIAM abrirá espaço crítico para uma releitura da obra sittiana:

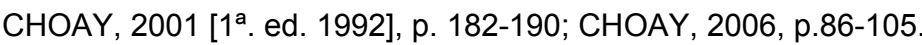


(14) Segundo Meyer (1990), é possível identificar traços de ambas as tendências na observação atenta das influências manifestadas em diversos estudiosos ao longo de toda a história do urbanismo, na variedade e especificidade de suas respectivas proposições: de um lado os teóricos mais afeitos à Camillo Sitte (Patrick Geddes, Lewis Munford e Jane Jacobs, por exemplo), e de outro, aqueles que dividem pontos em comum com Otto Wagner (Tony Garnier, Walter Gropius e Le Corbusier).

(15) Carta de Atenas, CIAM - Congresso Internacional de Arquitetura Moderna, 1933; consultar sobretudo o item n.69 (CARTAS PATRIMONIAIS, 2000, p.54). Os CIAM, Congressos Internacionais de Arquitetura Moderna, iniciaram-se em 1928, à princípio voltados ao tema da habitação e após 1930 debruçados principalmente sobre os problemas do urbanismo. Objetivavam discutir como os princípios teóricos da arquitetura moderna poderiam responder aos problemas causados pelo rápido crescimento urbano (CHOAY, 2003, p.19).

(16) BULS, 1893. Devido à dificuldade de acesso ao texto original em francês, neste estudo utilizaremos a tradução de Maria Pasolini, republicada como apêndice na versão italiana da obra de Marcel Smets (1999, p. 317-327).

(17) A este respeito, cabe ainda ressaltar a obra L'isolament des Veilles Eglises, onde o autor admite a necessidade de certas demolições e apresenta alguns critérios a respeito: "1. É necessário liberar as velhas igrejas das construções banais a ela adossadas, quando essas não apresentem nenhum interesse artístico ou arqueológico; 2. Não é necessário isolar as antigas igrejas, mas conservar-lhes, o mais possível, a velha 'moldura' [...] 3. Antes de modificar a velha 'moldura' das igrejas, será necessário estudar com cura as repercussões sobre o entorno imediato [...], [considerando inclusive] a contribuição que a igreja traz ao conjunto da praça pública." (BULS, 1910, p.28 apud GIAMBRUNO, 2001, p. 48-49, tradução nossa).

(18) Uma contribuição prática que conferiu à Buls certo prestígio foi a atuação sobre a Grand'Place de Bruxelas, evitando a sua destruição. Como burgomestre da cidade, Buls procurou conservar a praça e reconstruiu alguns de seus edifícios arruinados em 1850 com intuito de criar um encerramento visual e liberar o térreo ao tráfego de pedestres (SMETS, 1992, p. 83-84).

(19) STÜBBEN, 1890. Alguns trechos da obra, selecionados por Donatella Calabi, foram publicados em italiano em: PICCINATO, 1974.

(20) A esse respeito cabe destacar a publicação de manuais de construção urbana baseados no método proposto por Stübben. Na Itália, a editora Hoepli, dedicada desde o início do século 20 a títulos de caráter manualístico voltados a engenheiros e arquitetos, publicou em 1915 a obra organizada por Aristide Caccia. Fato que demonstra a considerável difusão de seus estudos naquele momento.

(21) A esse respeito, Jokilehto (2006, p.220) ressalta que as teorias de Stübben - de certa forma baseadas no desenvolvimento da cidade moderna sobre a cidade histórica, aproveitando-se das circunstâncias existentes teriam influenciado o Plano Diretor de Roma de 1908 que previa demolições e aberturas de novas vias sobre a cidade antiga, proposta posteriormente criticada por Giovannoni.

(22) A análise da repercussão do pensamento de Camillo Sitte sobre os teóricos aqui destacados foi realizada com base em CALABI, 1992, p. 50-57. Para um amplo panorama da repercussão dessas ideias na prática urbanística em diferentes países, consultar CALABI, PROFYRIOU, RETTO Jr., 2006. 
(23) Diversos autores indicam o modelo haussmanniano como principal norteador das obras de Pereira Passos na cidade do Rio de Janeiro. E sobre a repercussão dos estudos de estética urbana, alguns autores defendem a presença de certos aspectos desse pensamento nas propostas elaboradas por urbanistas paulistas como Victor da Silva Freire, Francisco Saturnino de Brito e Francisco Prestes Maia. Deve-se, contudo, considerar a abrangência dessa repercussão com cuidado. Apesar de alguns desses urbanistas abordarem o tema da estética urbana, na prática as prioridades de seus projetos eram sobretudo técnicas, vinculadas ao sistema viário. Para aprofundamentos e bibliografia complementar, consultar: CAMPOS, 2002; SIMÕES, 2008; TOLEDO, 1996; OLIVEIRA, 2008; CALABI et al, 2006.

\section{Referências Bibliográficas}

ANDRADE, Carlos Roberto Monteiro de. Apresentação. In: SITTE, Camillo. A construção das cidades segundo seus princípios artísticos. [1ª. ed. austríaca: 1889]. São Paulo: Ática, 1992.

ANGOTTI-SALGUEIRO, Heliana (Org.). Cidades capitais do século XIX. São Paulo: Edusp, 2001.

BAUMEISTER, Reinhard. Stadt-erweiterungen in technischer baupolizeilicher und wirthschaftlicher beziehung. Berlin: Korn, 1876.

BENEVOLO, Leonardo. História da arquitetura moderna. São Paulo: Perspectiva, 2001.

BERTONI, Angelo. Camillo Sitte e il movimento del "L'Art public": congressi internazionali ed esperienze locali in Belgio e in Europa francofona tra il 1890 e il 1914. In: CALABI, D. et al (Org.). Anais do I Congresso de História Urbana. Bauru: Cultura Acadêmica Editora; FAPESP, 2006. p. 1-18.

BIANCHETTI, Cristina. Arte urbana e memoria disciplinare. In: SMETS, M. Charles Buls: i principi dell'arte urbana. Roma: Officina, 1999.

BOHL, Charles; LEJEUNE, Jean-François (Eds). Sitte, Hegemann and the metropolis: modern civic art and international exchanges. New York: Routledge, 2008.

BROERMAN, E. L'art appliqué à la rue et aux objets d'utilité publique. Bruxelles: Alfred Castaigne Editeur, 1895.

BULS, Charles. Esthétique des Villes. Brussels: Bruyland-Christople, 1893.

Estetica delle città. Trad. Maria Pasolini. In: SMETS, Marcel. Charles Buls: i principi dell'arte urbana (appendice). Roma: Officina, 1999.

La restauration des monuments anciens. Bruxelles: Weissenbruch, 1903.

L'isolament des Veilles Eglises. Bruxelles: Librairie Nationale D'Art et D'Histoire, 1910. 
CACCIA, Aristide. Costruzione, trasformazione ed ampliamento delle città, compilato sulla traccia dello Städtebau di J. Stübben: ad uso degli ingegneri, architetti, uffici tecnici ed amministrazioni municipali. Milano: Hoepli, 1915.

CALABI, Donatella. L'arte urbana in Europa: alcuni categorie concettuali nelle parole dei suoi teorici. In: SPAGNESI, Gianfranco (Org.). L'Architettura delle Trasformazioni Urbane 1890-1940. Roma: Centro di Studi per la Storia dell'Architettura, 1992.

O papel de Paris na urbanística italiana do século XIX: o mito da modernização. In: ANGOTTISALGUEIRO, Heliana (Org.). Cidades capitais do século XIX. São Paulo: Edusp, 2001.

CALABI, Donatella; PROFYRIOU, Heleni; RETTO Jr., Adalberto da Silva (Orgs.). Anais do I Congresso de História Urbana: Camillo Sitte e a circulação da ideias de estética urbana. Europa e América Latina: 1880-1930. Bauru: Cultura Acadêmica Editora FAPESP, 2006.

CAMPOS Neto, Cândido Malta. Os rumos da cidade: urbanismo e modernização em São Paulo. São Paulo: Senac, 2002.

CARTA de Atenas, 1933. CIAM - Congresso Internacional de Arquitetura Moderna. In: Cartas Patrimoniais. Rio de Janeiro: IPHAN, 2000, p. 21-68.

CERDÁ, Ildefonso. La teoría general de la urbanización y aplicación de sus principios y doctrinas a la reforma y ensanche de Barcelona. Madrid: Imprenta Española, 1867.

CHOAY, Françoise. A alegoria do patrimônio [1ª. ed. francesa: 1992]. Tradução Luciano Vieira Machado. São Paulo: Estação Liberdade; Unesp, 2001.

Pour une antropologie de l'espace. Paris: Éditions du Seuil, 2006.

O urbanismo: utopias e realidades, uma antologia. [1ª. ed. francesa: 1965]. Tradução Dafne Rodrigues. São Paulo: Perspectiva, 2003.

COLLINS, C. C. Christiane Crasemann Collins e trajetórias transatlânticas. Vitruvius, São Paulo, n. 06.022, abr. 2005. Entrevista concedida a Adalberto da Silva Retto Junior. Disponível em: http://vitruvius.com.br/revistas/read/entrevista/06.022/3316. Acesso em: 2 abr. 2012.

COLLINS, C. C.; SEMSROTH, K.; MÖNNINGER, M. Camillo Sitte: Gesamtausgabe. Vienna: Böhlau, 2008-2011. $6 \mathrm{v}$.

COLLINS, G. R.; COLLINS, C. C. Camillo Sitte and the birth of modern city planning. New York: Random House, [1965].

DE FUSCO, Renato. Storia dell'architettura contemporanea. Roma: Laterza, 2000.

DVOŘÁK, Max. Catecismo da preservação de monumentos. [1ª edição 1916]. Tradução Valéria Alves Esteves Lima. Cotia, SP: Ateliê Editorial, 2008. 
GIAMBRUNO, Mariacristina. L'opera di Charles Buls: dall'estetica delle città al restauro dei monumenti. Ananke, nuova serie, n. 31, p. 46-52, 2001.

GIULIANI, Aldo. Monumenti, Centri Storici, Ambiente. Milano: Tamburi, 1966,

JOKILEHTO, Jukka. A history of architectural conservation. [1 ${ }^{\mathrm{a}}$. ed. inglesa: 1999]. Oxford: ButterworthHeinemann, 2006.

LE CORBUSIER. Urbanisme. Paris: Crès, 1923.

MEYER, Regina Prosperi. Urbanismo à procura do espaço perdido. Revista USP, São Paulo, n. 5, Dossiê Cidades, 1990.

MORRIS, William. The Society for the Protection of Ancient Buildings [1877]. In: SPAB, repair, not restoration. London: The S.P.A.B., 1977. [Tradução de Maria Lucia Bressan Pinheiro anexa ao artigo: PINHEIRO, M. L. B. William Morris e a SPAB. Rotunda, n. 3, out. 2004, p. 22-35]. . Disponível em: < http://www.iar.unicamp.br/rotunda/rotunda03.pdf>. Acesso em: 3 abr. 2012].

OLIVEIRA, Fabiano Lemes de. Modelos urbanísticos modernos e parques urbanos: as relações entre urbanismo e paisagismo em São Paulo na primeira metade do século XX. Tese (Doutorado). Barcelona: Universidad Politécnica de Catalunya, 2008.

PICCINATO, Giorgio. La costruzione dell'urbanistica: Germania 1871-1914. Roma: Officina, 1974.

PICCINELLI, A. Monneret de Villard e la versione italiana. In: ZUCCONI, G. (Org.). Camillo Sitte e i suoi interpreti. Milano: Franco Angeli, 1992.

PINON, Pierre. Atlas de Paris Haussmannien. Paris: Parigramme, 2002.

RÉAU, Louis (Org.). L'oeuvre du Baron Haussmann, Préfet de la Seine (1853-1870). Paris: PUF, 1954.

RONCAYOLLO, Marcel; PAQUOT, Thierry. Villes \& Civilisation Urbaine, XVIIle-XXe siècle. Paris: Larousse, 1992.

RUFINONI, Manoela. Preservação e restauro urbano: teoria e prática de intervenção em sítios industriais de interesse cultural. Tese (Doutorado)-Faculdade de Arquitetura e Urbanismo, Universidade de São Paulo, São Paulo, 2009.

RUSKIN, John. A lâmpada da memória. Tradução Maria Lucia Bressan Pinheiro. Cotia,SP: Ateliê Editorial, 2008, p. 56. [Tradução brasileira do capítulo The Lamp of Memory. In: RUSKIN, J. The seven lamps of architecture, $1^{\mathrm{a}}$ ed. 1849].

SIMÕES Jr., José Geraldo. A urbanística germânica (1870-1914): internacionalização de uma prática e referência para o urbanismo brasileiro. Arquitextos Vitruvius, n. 097.03, 2008. Disponível em: http://vitruvius.com.br/revistas/read/arquitextos/09.097/134. Acesso em: 2 abr. 2012. 
SMETS, Marcel. L'avènement de la cité-jardin cidade jardin en Belgique: histoire de l'habitat social en Belgique de 1830 à 1930. Liège: Pierre Mardaga, 1977.

Charles Buls: les principes de l'art urbain. Liège: Pierre Mardaga, 1995.

Charles Buls et l'amorce d'une nouvelle politique urbaine a la fin du $19^{\text {eme }}$ siècle. In: SPAGNESI, Gianfranco (Org.). L'Architettura delle trasformazioni urbane 1890-1940. Roma: Centro di Studi per la Storia dell'Architettura, 1992.

SITTE, Camillo. A construção das cidades segundo seus princípios artísticos [1 ${ }^{\text {a }}$. edição austríaca: 1889]. Tradução Ricardo Ferreira Henrique. São Paulo: Ática, 1992.

STÜBBEN, Joseph. Der Städtebau (Handbuch Der Architektur). Darmstadt: Bergsträsser, 1890.

TOLEDO, Benedito Lima de. Prestes Maia e as origens do urbanismo moderno em São Paulo. São Paulo: Empresa das Artes, 1996.

WIECZOREK, D. Camillo Sitte et les débuts de l'urbanisme moderne. Bruxelles: Pierre Mardaga, [1981].

ZUCCONI, Guido. A cidade do século XIX. São Paulo: Perspectiva, 2009

Sitte, I'Italia e il tema dei centri monumentali. In: CALABI, D. et al. (Org.) Anais do I Congresso de História Urbana. Bauru: Cultura Acadêmica Editora; FAPESP, 2006

ZUCCONI, Guido (Org.). Camillo Sitte e i suoi interpreti. Milano: Franco Angeli, 1992.

\section{Créditos}

*Arquiteta urbanista, doutora pela FAUUSP, docente da Escola de Filosofia, Letras e Ciências Humanas da Universidade Federal de São Paulo, Departamento de História da Arte.

rufinoni@unifesp.br

Pesquisa elaborada com o apoio do Conselho Nacional de Desenvolvimento Científico e Tecnológico 